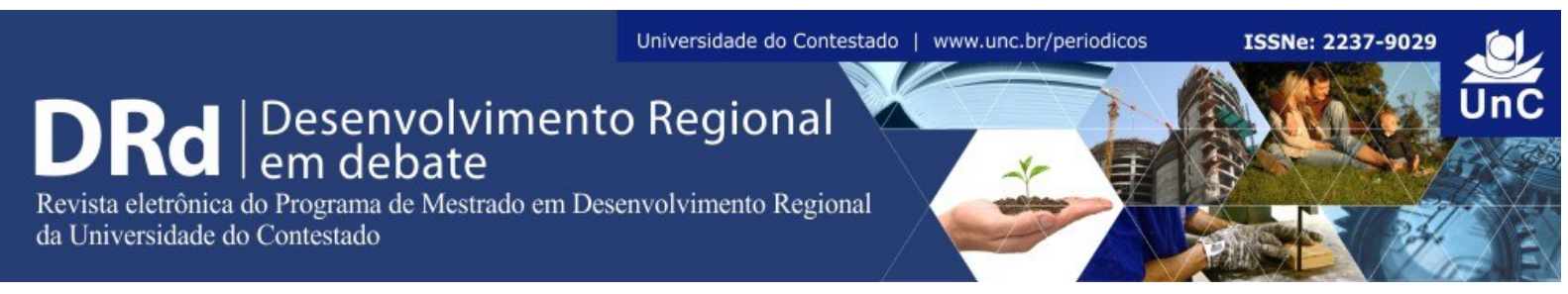

\title{
SAÚDE E DESENVOLVIMENTO: UMA ANÁLISE A PARTIR DO CONCEITO DE DESENVOLVIMENTO DE AMARTYA SEN
}

Aline Fernanda Fischborn ${ }^{1}$

\section{RESUMO}

O artigo propõe uma discussão sobre o conceito ampliado de saúde construído a partir da legalização do Sistema Único de Saúde (SUS) na Constituição federal de 1988, em especial, consolidado através das Estratégias de Saúde da Família (ESF) com as ideias sobre desenvolvimento defendidas pelo economista Amartya Sen. Parte-se do pressuposto que a saúde abrange aspectos amplos e complexos, tais como questões sociais, econômicas, políticas e ambientais e quando entendida dessa forma, dialoga com as ideias apresentadas por Sen em seu livro Desenvolvimento como Liberdade. O presente artigo pretende assim, trazer as aproximações entre os ideais e ações da Política de Saúde vigente no Brasil, em especial no que tange a Atenção Básica e os conceitos defendidos por Sen. Conclui-se que os avanços alcançados pelo SUS, fazem dessa política de saúde um modelo mundial, na medida em que incentiva o desenvolvimento focado nas pessoas e na sua condição de vida buscando a construção de cidadãos livres.

Palavras-Chave: Saúde. Desenvolvimento. Liberdade.

\section{AN ANALYSIS OF AMARTYA SEN DEVELOPMENT CONCEPT AND ITS CONTRIBUTION IN THE HEALTH AREA}

\begin{abstract}
This paper proposes a discussion on the broad concept of health built from the legalization of the Unified Health System (SUS) in the Federal Constitution of 1988, in particular through the Consolidated Health Strategies Family (ESF) with ideas about development advocated by economist Amartya Sen. It is proposed the assumption that health encompasses large and complex aspects such as social, economic, political and environmental and when understood in this way, dialogue with the ideas presented by Sen in his book Development as Freedom . This article aims to thus bring the similarities between the ideals and actions of the current Health Policy in Brazil, in particular with respect to primary care and the concepts advocated by Sen. It is concluded that the advances achieved by SUS, make a global health policy model, in that it encourages the development focused on people and their living conditions seeking the construction of free citizens.
\end{abstract}

Keywords: Health. Development. Freedom.

\footnotetext{
${ }^{1}$ Doutoranda em Desenvolvimento Regional pela Universidade de Santa Cruz do Sul - UNISC. Docente do Curso de Enfermagem da Universidade de Santa Cruz do Sul - UNISC. Santa Cruz do Sul. Rio Grande do Sul, Brasil. E-mail: fischborn@unisc.br
} 


\section{INTRODUÇÃO}

A partir da Constituição Federal de 1988, a saúde no Brasil passou por mudanças significativas e que proporcionaram qualidade de vida à população, em especial no que tange o acesso aos serviços de saúde de forma gratuita. Houveram mudanças no modelo de atenção vigente, aumento do acesso aos serviços e melhoras consideráveis nos indicadores de saúde. Todos esses avanços vieram no bojo crescente da democratização das ações em saúde ainda que num contexto neoliberal e numa perspectiva de mundialização da economia iniciada por volta da década de 80 no Brasil.

O foco da política de saúde na Atenção Primária, respaldada pelo Sistema Único de Saúde (SUS), culminou com programas, projetos e estratégias, tais como a Estratégia de Saúde da Família (ESF) que vieram para celebrar e unir as intenções de aplicação de um conceito ampliado de saúde, promovendo ações sociais no sentido de fortalecer a cidadania da população.

Tal movimento dialoga com o modelo de desenvolvimento criado pelo economista Amartya Sen. O autor afirma que é impossível pensar em desenvolvimento aos indivíduos privados de liberdades essenciais. Nessa perspectiva, o desenvolvimento não está atrelado unicamente ao crescimento econômico, mas perpassa áreas fundamentais do indivíduo e da sociedade, como acesso aos serviços de saúde, educação e cidadania. Para Sen, "[...] o desenvolvimento consiste na eliminação de privações de liberdade que limitam as escolhas e as oportunidades das pessoas de exercer ponderadamente sua condição de agente" (SEN, 1999, p.10).

Nesse sentido, o presente trabalho não tem a pretensão de expor as diversas contradições presentes na implantação da política de saúde e tão pouco fazer uma análise macrossocial do paradoxo que se estabelece entre um movimento de democratização da saúde e um avanço das políticas neoliberais, ainda que não ignoremos tais movimentos. Pretende-se fazer breve revisão sobre a implantação do SUS e da aplicabilidade dos seus princípios e conceitos na ESF em busca de atender ao novo conceito de saúde, aproximando tais preceitos ao modelo de desenvolvimento como liberdade defendido por Sen. Para isso, fez-se uma revisão bibliográfica no que tange os conceitos relacionados com a saúde e um aprofundamento bibliográfico sobre o livro Desenvolvimento como Liberdade de Sen. Nesse sentido pretende-se mostrar que a política de saúde do Brasil configura-se como um avanço e como uma forma de auxiliar na construção das liberdades individuais e coletivas da sociedade.

\section{CONSTRUÇÃO DO SUS: A DEMOCRATIZAÇÃO DA SAÚDE}

A saúde, em meados dos anos de 1980 iniciou um processo de transformação complexo e importante que teve como fio condutor, a democratização da saúde, envolvendo a democratização das ações, dos atendimentos e dos fluxos, e uma nova orientação no modo de trabalhar na saúde. Ainda que distante dos ideais amplos de uma reforma geral na sociedade 
defendida pelo movimento de Reforma Sanitária Brasileira (RSB), é inegável os avanços no setor saúde ao longo do seu processo (PAIM, 2008).

Com a Constituição Federal de 1988, e a implementação do Sistema Único de Saúde, mesmo em meio a contradições gritantes entre o projeto da RSB e o seu processo, coroando apenas de forma parcial os ideais da RSB, percebeu-se um impulso legal em tais transformações propostas para o setor.

Conceitualmente quando falamos de Sistema Único de Saúde, segundo Bahia,

Sistema deve ser entendido como o conjunto de ações e instituições, que de forma ordenada e articulada contribuem para uma finalidade comum, qual seja, a perspectiva de ruptura com os esquemas assistenciais direcionados a segmentos populacionais específicos, quer recortados segundo critérios socioeconômicos, quer definidos através de critérios nosológicos (BAHIA, 2008, p. 357).

A Constituição Federal de 1988 contribuiu, através da implantação do SUS, com importantes políticas descentralizadoras e na perspectiva de construção de uma nova forma de pensar e fazer saúde. A saúde passa a ser vista como direito do cidadão e dever do Estado, fato esse, que pode ser considerado inédito na história brasileira, tendo em vista que até então, a garantia da saúde estava atrelada a previdência social e vinha num processo crescente de privatizações. Os princípios norteadores do SUS são universalidade, integralidade e equidade. Assim, cabe ao Estado à obrigação de prover a saúde a todos os cidadãos de forma integral e de caráter universal, com acesso igualitário dos usuários aos serviços, sendo estes hierarquizados e a sua gestão descentralizada com participação da população (WEIGELT, 2006).

Segundo Pereira e Lima (2008), a proposta do SUS vai ao encontro de uma reforma social, com a construção de um estado democrático, posiciona a saúde como prática social e nãoapenas como fenômeno biológico, sendo que o sistema é responsável atualmente pelo atendimento exclusivo de 140 milhões de pessoas, ou $75 \%$ da população brasileira (MENDES, 2013).

O Sistema fez desaparecer a figura do indigente sanitário, no momento em que garantiu legalmente acesso ao serviço de saúde a todos, independente de serem portadores da carteira do INAMPS, fato esse, que separava aqueles que teriam acesso a uma assistência curativa razoável, daqueles que eram indigentes sanitários (MENDES, 2013).

Dessa forma, as ações que o SUS abarca vão desde ações de promoção, vigilância e educação em saúde, até a garantia de cuidados especializados a nível ambulatorial e hospitalar. As atenções, porém, tem sido voltada, de forma especial, para a saúde primária, ou a chamada, atenção básica, no sentido de entender a saúde não apenas como ausência de doenças, mas como algo amplo que perpassa aspectos sociais, ambientais, econômicos e políticos. Nesse contexto de prevenção e promoção a saúde, que se insere o Programa de Saúde da Família - PSF, criada em 1994, hoje denominado de Estratégia de Saúde da Família - ESF. 


\section{ESTRATÉGIA DE SAÚDE DA FAMÍLIA: UM NOVO MODELO DE ATENÇÃo A SAÚDE}

No sentido de fazer cumprir o que está legalizado pela Constituição Federal, dentre outras várias medidas, o Ministério da Saúde, em 1994 cria o Programa de Saúde da FamíliaPSF. Esta implementação fundamentou-se basicamente nos eixos da universalidade, integralidade e equidade, em um contexto de descentralização e controle social da gestão. Tal programa mais tarde foi substituído conceitualmente pela Estratégia de Saúde da Família ESF.

Assim, a ESF pode ser considerada uma estratégia governamental para reorganizar o sistema de saúde e o modelo de atenção à saúde. Pensar e fazer saúde passam a estar desvinculado do modelo biomédico e curativo, no sentido de construção de um novo conceito de saúde, contemplando visitas domiciliares, atendimento diferenciado ao usuário com foco na prevenção e promoção a saúde. Para Matta e Morosini (2008), a saúde abrange as condições de habitação, alimentação, educação, renda, trabalho, meio ambiente, transporte, lazer, liberdade, acesso e posse de terra e acesso à serviços de saúde. Nas ESF a proposta é contemplar todas essas esferas, considerando a saúde também como forma de cidadania e democracia.

As equipes de saúde que atuam nesse serviço são compostas por no mínimo um médico, um enfermeiro, um técnico ou auxiliar de enfermagem e de quatro a seis agentes comunitários de saúde. Quando ampliada, tal estratégia pode contemplar ainda o Programa de Saúde Bucal, com a atuação de um dentista, um auxiliar de consultório dentário e/ou um técnico em higiene dental. Cada equipe se responsabiliza pelo acompanhamento de, no máximo, quatro mil habitantes ou mil famílias. Assim, o atendimento direciona-se para a família, entendendo a sua dinâmica e seu local de moradia como condicionantes do processo saúde/doença.

Para o Ministério da Saúde,

[...] a atuação das equipes ocorre principalmente nas unidades básicas de saúde, nas residências e na mobilização da comunidade, caracterizando-se: como porta de entrada de um sistema hierarquizado e regionalizado de saúde; por ter território definido, com uma população delimitada, sob a sua responsabilidade; por intervir sobre os fatores de risco aos quais a comunidade está exposta; por prestar assistência integral, permanente e de qualidade; por realizar atividades de educação e promoção da saúde (BRASIL, 2012, p.10).

Na prática, a ESF busca fortalecer o vínculo entre a comunidade e a equipe, através da confiança mútua facilitada pelo atendimento periódico e sistemático das mesmas famílias; a promoção da saúde e prevenção da doença de maneira permanente e em loco (na casa onde vive a família); a promoção de discussões dos casos de saúde das famílias com um olhar interdisciplinar dos vários integrantes da equipe de saúde; facilitar o acesso do usuário ao serviço de saúde, tendo em vista que cada equipe fica responsável por um número limitado de famílias em uma área geográfica definida; estimular a educação em saúde da população a fim de promover a autonomia individual e coletiva; incentivar ações de gestão local e controle social por parte da população; entre tantos outros objetivos que tem como fim, a qualidade de vida do usuário. 
Cabe ao município definir a área de implantação da ESF, sendo estimulada pelo governo federal uma cobertura de $100 \%$ da população atendida pelas equipes de saúde. Como muitos municípios não tem a contrapartida financeira necessária para atingir a meta ideal de cobertura opta-se por localizar as ESF em áreas de vulnerabilidade social, com problemas de saneamento, indicadores de saúde desfavoráveis, baixa adesão à escola, entre outros. Assim, percebe-se a ESF como estratégia de garantia de acesso a saúde dessa população que vive em condições precárias, muitas vezes distantes de centros de saúde e que dependem do serviço público de saúde. Bousquat, Gomes e Alves (2012), em uma pesquisa recente realizada no município de Santo André (SP), verificaram que os moradores que não frequentam as unidades de saúde estão na faixa etária entre 21 e 59 anos, trabalham e são afiliados ao subsistema privado de saúde e possuem maior renda.

Segundo Mendes (2013), as ESF cobrem atualmente 58\% da população brasileira com mais de 32 mil equipes de saúde da família espalhadas por quase todos os municípios brasileiros. Ainda dados indicam que a ESF influência positivamente no acesso a serviços e utilização dos serviços de saúde, atingindo diretamente a saúde dos brasileiros, reduzindo a mortalidade infantil e de crianças menores de cinco anos, tendo impacto na morbidade, com evidente foco nos mais pobres, aumentando a satisfação das pessoas com o atendimento recebido, melhorando os índices gerais do SUS, e também contribuindo para aumentar o interesse de vários países para as ações em atenção primária.

Assim, as ações de educação em saúde da rede básica devem primar pelo envolvimento do usuário nas ações de saúde, estimulando o autocuidado, promovendo um diálogo entre equipe e usuário de forma não hierárquica e respeitando a cultura individual de cada usuário. Para Morosini, Fonseca e Pereira (2008) fazer educação em saúde na perspectiva do SUS deve passar pela estimulação da ação política de indivíduos e sociedade no sentido de pensar a saúde de maneira social, cultural, ética, política e científica. Assim, trabalhadores juntamente com a população assistida passam a ser sujeitos do processo de produção dos cuidados em saúde.

Nesse sentido, para Pereira e Barros (2008), o aumento do grau de comunicação entre a equipe e entre a equipe e usuário, bem como o aumento do grau de corresponsabilidade no cuidado são fundamentais para a construção dos sujeitos envolvidas na prática de saúde, como protagonistas das suas ações e não meros receptores.

Morosini, Fonseca e Pereira (2008) alerta ainda que o conceito de saúde ampliada, não abrange apenas garantir ao usuário o acesso ao serviço de saúde, o que é fundamental, porém não suficiente, já que não se pode desconsiderar a necessidade de garantir condições de vida digna ao usuário. Tais condições somadas, acesso ao serviço e vida digna, podem proporcionar uma situação de saúde melhor ao usuário e família, não podendo, dessa forma, desvincular saúde e direito social.

Dessa forma, percebe-se que a proposta da democratização da saúde via SUS e a implementação de novo modelo de atenção à saúde via ESF, ainda que apresentem problemas na sua real implantação, caminham no sentido de promover e estimular a autonomia do indivíduo e a coletividade em vários aspectos da sua vida, entendendo que o individuo saudável deve ser autônomo, participativo e protagonista das ações que permeiam a sua vida. 


\section{DESENVOLVIMENTO COMO LIBERDADE: APROXIMAÇÕES COM O CONCEITO AMPLIADO DE SAÚDE}

É no contexto descrito acima que segue as aproximações entre os caminhos percorridos pela política de saúde no Brasil no sentido de democratização dos processos e autonomia dos indivíduos e coletividades, com a abordagem do economista Amartya Sen no seu célebre livro Desenvolvimento como Liberdade.

Pensar no conceito de desenvolvimento não é tarefa fácil. A lógica capitalista tenta nos impor histórica e sistematicamente o desenvolvimento atrelado a crescimento econômico, industrialização, aumento do PIB, consumo, entre outros parâmetros que se analisado isoladamente nos dizem pouco sobre o real desenvolvimento de uma região. Em contrapartida, temos autores e escolas com pensamentos contrários a essa visão. Tais ideias se sustentam nos questionamentos: Somos mais felizes por conta do progresso? O pensamento da lógica de mercado serve para quem e está em busca de quê? Será que estamos dispostos a ter crescimento econômico a todo custo? Ter crescimento econômico significa melhoria de qualidade de vida a toda a população? Crescer para quê?

É evidente que não se defende que o crescimento econômico não faça parte do desenvolvimento, porém ele não pode ser visto como a variável mais importante. Deve-se entender o desenvolvimento como potencialidade, algo que abranja uma visão interdisciplinar, em um território múltiplo, que satisfaça os multiatores envolvidos no processo (famílias, empresas, instituições, Estado). Falar em desenvolvimento desconsiderando as questões ambientais, sociais, éticas, culturais, econômicos e de território, seria olhar para o conceito de forma rasa, passiva e complacente, o que de fato dialoga com os interesses do mainstream.

Assim, se constrói o conceito elaborado por Amartya Sen para desenvolvimento, em que o foco na condição humana é essencial, sendo a liberdade o meio e o fim para se atingir o desenvolvimento. Ele defende que o indivíduo deve ser agente ativo nos processos, ter a liberdade de fazer escolhas pessoais e coletivas, o que, para ao autor, é impossível aos indivíduos que tem as suas capacidades básicas privadas.

Sen é criticado por muitos pensadores que alegam uma visão ingênua e utópica do capitalismo por parte dele, na medida em que estaria propondo um escape, uma saída, uma possibilidade dentro do próprio sistema capitalista. Não é foco desse trabalho fazer a discussão da viabilidade da sua proposta, uma vez que e a tentativa aqui, é mostrar que a atenção básica está avançando nesse sentido. Afinal, identificam-se traços e aproximações das suas ideias com os caminhos construídos e em construção pela política de saúde no Brasil, ainda que essa apresente as suas sabidas limitações e desafios.

O autor nos traz cinco tipos distintos de liberdades instrumentais que devem se articular para potencializar a liberdade humana geral, quais sejam: liberdades políticas, facilidades econômicas, oportunidades sociais, garantias de transparências e segurança protetora. O Estado e a sociedade têm papéis amplos de incentivo, difusão e proteção das capacidades humanas e devem agir de forma articulada. Para ele, 
[...] oportunidades sociais de educação e assistência médica, que podem requerer a ação pública, complementam oportunidades individuais de participação econômica e política e também favorecem nossas iniciativas para vencer privações (SEN, 1999, p. 10).

Assim, a liberdade plena estaria atrelada a esses cinco tipos instrumentais de liberdade, sendo que a avaliação discutida por esse artigo se aterá a liberdade como oportunidade social, através do acesso a serviços de saúde, ainda que esse tipo instrumental de liberdade também reflita na participação econômica e na segurança protetora. Afinal, segundo Sen (1999, p.26), "[...] com oportunidades sociais adequadas, os indivíduos podem efetivamente moldar seu próprio destino e ajudar uns aos outros".

É na forma de agente das ações que se pretende perceber o usuário do sistema de saúde, como coprodutor da sua saúde e não como receptor dos cuidados da equipe de saúde. No espaço da ESF, a aproximação e conhecimento da realidade de moradia, de trabalho e de vida dos usuários, favorece a construção de confiança, estimula a autonomia e a interação do indivíduo com o mundo.

No mesmo sentido, segundo Sen (1999), muitas pessoas por não terem acesso a serviço de saúde convivem com a morbidez desnecessária e muitas vezes com a morte prematura. Com a implantação do programa de atenção primária em saúde, que abrange as ESF, a taxa de mortalidade infantil entre 2000 e 2010, caiu 40\%. (MENDES, 2013). É sabido que muitas causas de óbito são facilmente evitáveis com medidas simples que podem ser implementadas pela equipe de saúde da família em parceria com o usuário e sua família. Também a estimulação de hábitos saudáveis considerando a realidade de vida e habitação das famílias, gera resultados rápidos e satisfatórios.

Como já exposto no decorrer do texto, as ESF são construídas prioritariamente em locais de vulnerabilidade social. Locais esses, que certamente desfavorecem a condição humana digna de viver, povoada por uma população que opta pela subsistência da sua família em detrimento de pagar um plano de saúde. População que depende do atendimento da saúde pública. População que tem na ESF um acolhimento digno, que é atendido por uma equipe multiprofissional preparada para fazer seu colhimento, seja na unidade básica de saúde, seja na sua residência. O usuário tem ainda oferta de medicamentos, acesso a grupos de saúde, encaminhamentos aos serviços de maior complexidade, entre tantas outras ações desenvolvidas à população de forma gratuita.

Para Mendes,

O SUS constitui a maior política de inclusão social da história do nosso país. Antes do SUS vigia um Tratado de Tordesilhas da saúde que separava quem portava a carteirinha do INAPS e tinha acesso a uma assistência curativa razoável das grandes maiorias que eram atendidas por uma medicina simplificada na atenção primária em saúde e como indigentes na atenção hospitalar. [...]. Fez desaparecer, definitivamente, a figura odiosa do indigente sanitário (MENDES, 2013, p.28).

Pergunta-se: essas pessoas teriam acesso a um serviço de qualidade se não fosse através da garantia de acesso universal a saúde através da Constituição Federal? Teriam suas necessidades humanas básicas saciadas ou amenizadas? De que forma, se não essa? 
Sen (2001) fez contribuições importantes e inovadoras também sobre o conceito de pobreza, sendo que para o autor, a pobreza não pode estar apenas atrelada as questões de renda e sim, fundamentalmente às condições de liberdade, ou melhor, às privações de liberdade. Para o autor, limitar a visão da pobreza apenas à renda configura-se em um grave erro no que tange questões éticas e morais.

$\mathrm{O}$ autor introduz o conceito de funcionamentos (functionings), defendendo que seriam um conjunto de ações e estados valiosos para o viver humano, os quais vão desde as questões elementares, como estar adequadamente nutrido e livre de doenças evitáveis, até as mais complexas, como ter respeito próprio e participar da vida comunitária (SEN, 1999). Sendo a saúde um dos principais funcionamentos a que o indivíduo deve ter acesso, todos os fatores que impeçam o seu alcance, tais como habitações precárias e insalubres, desemprego, fome entre outros, configuram fontes de privação e limitação de acesso à liberdade. $\mathrm{O}$ autor lembra que as vantagens que um indivíduo possui podem ser muito melhor representadas pela liberdade que esta pessoa usufrui e por aquilo que ela realiza com base nesta liberdade (SEN, 1999).

Apesar dos funcionamentos serem individuais e singularmente representativos, Sen (1999), lembra que existem alguns funcionamentos que são essenciais para uma vida digna, quais sejam: alimentação adequada, escapar da morte prematura e estar livre de doenças que podem ser evitadas.

Assim, no caminho do que Sen aponta, uma pessoa saudável, no sentido do conceito ampliado de saúde é uma pessoa mais disposta para o trabalho, para a participação da educação de seus filhos, para promoção do autocuidado, para realizar o controle social do serviço, é uma pessoa que se sente valorizada e estimulada a buscar conhecimento e desenvolver o seu local de moradia, enfim, seria um cidadão livre.

\section{CONSIDERAÇÕES FINAIS}

Sabendo das limitações desse trabalho e sem a pretensão de esgotar as discussões a cerca do tema, entende-se que os ideais do SUS, muitos deles implementados através das ESF, levam em conta o desenvolvimento pessoal e coletivo do usuário, caminhando no sentido de conhecer e de valorizar a condição humana.

$\mathrm{Na}$ teoria defendida por Amartya Sen, a qual lhe garantiu o Prêmio Nobel de Economia em 1998, há um deslocamento do ter no sentido da ser e fazer, o que o diferencia dos teóricos tradicionais, que numa linha positivista, consideram as posses de bens e mercadorias como sinônimo de riqueza individual, coletiva e como marca de desenvolvimento de um país.

Um desenvolvimento que preza apenas aspectos econômicos e que não priorize o acesso a serviços de saúde, não se pode dizer completo. Um desenvolvimento que prime pelo aumento das indústrias, mas desconsidere a condição de cidadão de seu trabalhador, não pode ser visto como desenvolvimento. Desenvolvimento que não alie condições de moradia e educação à população poderia ser considerado um desenvolvimento incompleto. 
Estimular a autonomia dos sujeitos, a participação nas discussões, o acesso à saúde de forma simples e ágil, são premissas do SUS, que, sem ignorar seus limites e problemas, vem sendo cumpridas. Percebe-se dessa forma, uma política que serve de modelo para o mundo, no que tange as políticas públicas de saúde, no sentido de ser um modelo de desenvolvimento focado nas pessoas e na sua condição de vida. Pode ser considerado também um modelo de desenvolvimento, na medida em que objetiva tornar seus usuários livres e saudáveis.

O aspecto inovador desse trabalho passa pela aproximação da política de saúde com os conceitos trazidos por Amartya Sen, além de apresentar as ideias desenvolvidas pelo autor, no seu livro Desenvolvimento como Liberdade, às áreas sociais e humanas como uma possibilidade mais promissora de se pensar sobre desenvolvimento. Mostra-se uma visão atrelada ao papel do Estado e da própria sociedade, que preserva uma visão de possibilidade, não ignorando os condicionantes impostos pelas estruturas sociais.

\section{REFERÊNCIAS}

BAHIA, L. Sistema Único de Saúde. In: PEREIRA, I. B.; LIMA, J. C., F. (org.). Dicionário da Educação profissional em saúde. 2.ed. Rio Janeiro: EPSJV, 2008. p. 357-364.

BOUSQUAT, A.; GOMES, A.; ALVES, M. C. Acesso realizado ao Programa de Saúde da Família com área com "alta" cobertura do subsistema privado. Ciência \& Saúde Coletiva, v. 17, n. 11, p. 2913-2921, 2012.

BRASIL. Ministério da Saúde. Constituição da República Federativa do Brasil de 1988. Disponível em http://portal.saude.gov.br/portal/saude/cidadao/area.cfm?id_area=149. Acesso em: 12 dez.2012.

MATTA, G. C.; MOROSINI, M. V. G. Atenção à saúde. In: PEREIRA, I. B.; LIMA, J. C. F. (org.). Dicionário da Educação profissional em saúde. 2.ed. Rio Janeiro: EPSJV, 2008. p. $39-44$.

MENDES, E. V. 25 anos do Sistema Único de saúde: resultados e desafios. Estudos Avançados, v. 27, n. 78, p. 27-34, 2013.

MOROSINI, M. V.; FONSECA, A. F.; PEREIRA, I. B. Educação em saúde. In: PEREIRA, I. B.; LIMA, J. C. F. (Org.) Dicionário da educação profissional em saúde. 2.ed. Rio Janeiro: EPSJV, 2008. p. 155-162.

PAIM, J. P. Reforma Sanitária Brasileira, contribuição para a compreensão e crítica. Rio de Janeiro: Editora Fiocuz, 2008.

PEREIRA, I. B.; LIMA, J. C. F. Trabalho, Educação e Saúde: referências e conceitos. In: PEREIRA, I. B.; LIMA, J. C. F. (Org.). Dicionário da educação profissional em saúde. 2.ed. Rio Janeiro: EPSJV, 2008. p. 17-28. 
PEREIRA, E. H. P.; BARROS, R. D. B. Humanização. In: PEREIRA, I. B. L.; LIMA, J.C.F (Org.). Dicionário da educação profissional em saúde. 2.ed. Rio Janeiro: EPSJV, 2008. p. 243-248.

SEN, A. Desenvolvimento como liberdade. São Paulo: Companhia das letras. 1999.

Desigualdade reexaminada. São Paulo: Record, 2001.

WEIGELT, L. D. Política pública de saúde: um estudo sobre o processo de implementação da descentralização/regionalização da saúde na região do Vale do Rio Pardo-RS. 2006. Tese (Doutorado em Desenvolvimento Regional) - Universidade de Santa Cruz do Sul. Santa Cruz do Sul, 2006.

Artigo recebido em: 24/05/2014

Artigo aprovado em: 23/03/2015 